\title{
25. SURVEY AT SITE 337, NEAR THE EXTINCT AXIS IN THE NORWAY BASIN
}

\author{
M. Talwani and S. Sandal, Lamont-Doherty Geological Observatory \\ of Columbia University, Palisades, New York
}

In order to explain the asymmetric position of the presently active Iceland-Jan Mayen Ridge, Johnson and Heezen (1967) suggested the possibility that an earlier spreading axis may have existed in the Norway Basin, but had shifted to a position west of the Jan Mayen Ridge. This early spreading center would have been associated with the now extinct axis. Vogt et al., (1970) examined two magnetic profiles which appeared to be symmetrical and have given an age of 42 m.y. for the axis of symmetry. Le Pichon et al. (1971) using the same profiles suggested an age of 49 m.y.

By examining a number of profiles in the area, Talwani and Eldholm (in press) have confirmed the presence of symmetrical magnetic anomalies. They discovered that the extinct axis is associated with a welldefined topographic valley. The seismic reflection results obtained by Talwani and Eldholm showed a large thickness of sediments in the axial valley-thicknesses being generally in excess of $0.8 \mathrm{sec}$ (two-way travel time) and, in some cases, even exceeding $1.5 \mathrm{sec}$. High mountains exist on either side of this extinct spreading axis. The thickness of sediments is small on these mountains and is highly variable, ranging from zero in areas in which rocks outcrop to several tenths of seconds. Therefore it was necessary to run a precise site survey to delineate areas where the thickness of sediment would be large enough to obtain adequate sedimentary data, but small enough to be sure to reach basement.

A special site survey was run on Vema Cruise 30 during which bathymetry, gravity, magnetics, and seismic reflection data were obtained. A track chart of the Vema 30 survey is shown in Figure I together with tracks from earlier Vema surveys. The maps depicting geophysical data in Figures 2, 3, 4, and 5 are primarily based on the data obtained during this survey, but also incorporate earlier Vema data.

Figure 2 shows the bathymetry. Figure 3 is a total intensity magnetic map of the area on which the regional field has been removed. The magnetic pattern is clearly lineated. Figure 4 is a sediment isopach map and the seismic reflection records on profiles HG, GA, and DA are shown in Figure 5. These records clearly show the large variation in sediment thickness on the topographic high east of the extinct rift. This variation is largely due to the roughness of the basement topography.

\section{ACKNOWLEDGMENTS}

Support for this work came from Contracts N00014-67-A0108-0004 and N00014-75-C-0210 with the U.S. Office of Naval Research and from Grants GA2434, GP5392, GA17731, GA27281, and DES71-00214-A07 from the National Science Foundation.

\section{REFERENCES}

Johnson, G.L. and Heezen, B.C., 1967. Morphology and evolution of the Norwegian-Greenland Sea: Deep-Sea Res., v. 14, p. 755-771.

Le Pichon, X., Hyndman, R.D., and Pautot, G., 1971. Geophysical study of the opening of the Labrador Sea: J. Geophys. Res., v. 76, p. 4724-4743.

Talwani, M. and Eldholm, O., in press. Evolution of the Norwegian-Greenland Sea: Geol. Soc. Am. Bull.

Vogt, P.R., Ostenso, N.A., and Johnson, G.L., 1970. Magnetic and bathymetric data bearing on sea-floor spreading north of Iceland: J. Geophys. Res., v. 75, p. $903-920$. 


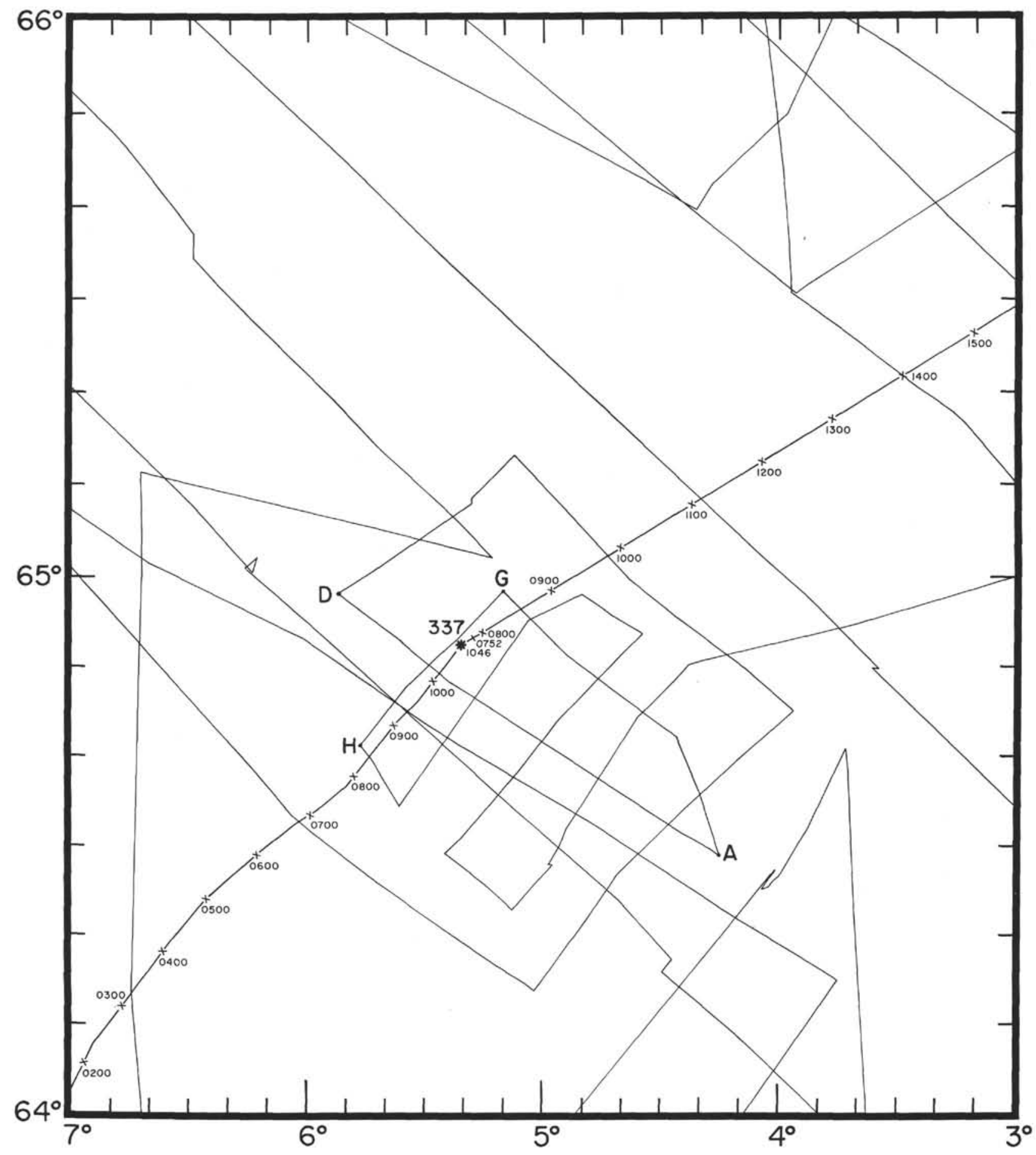

Figure 1. Tracks of Vema Cruises 27,28,29, and a detailed survey during cruise 30. The heavy line gives the track of Glomar Challenger. 


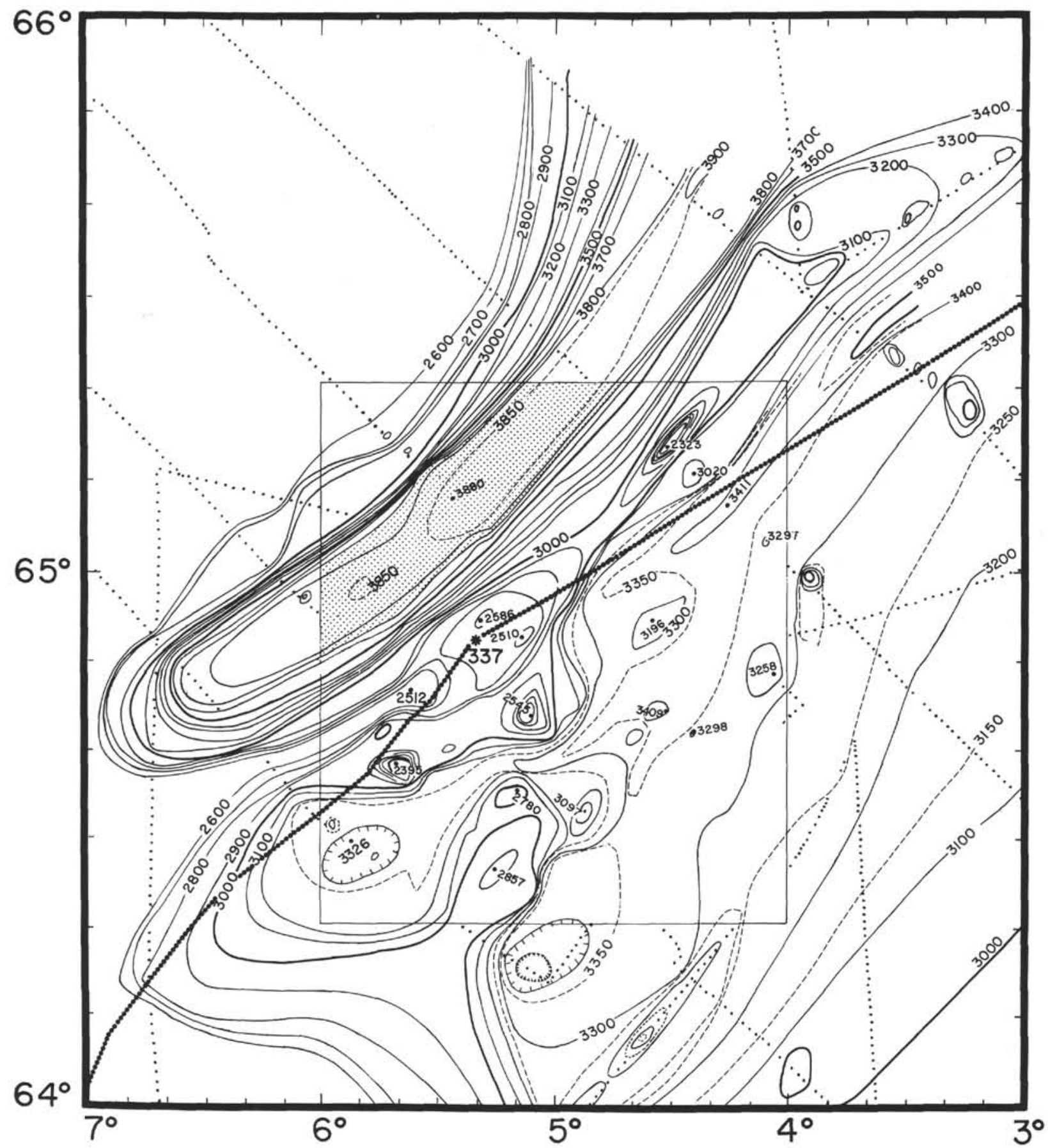

Figure 2. Bathymetric chart in corrected meters. Depths greater than 3700 meters in the extinct rift are shaded. 


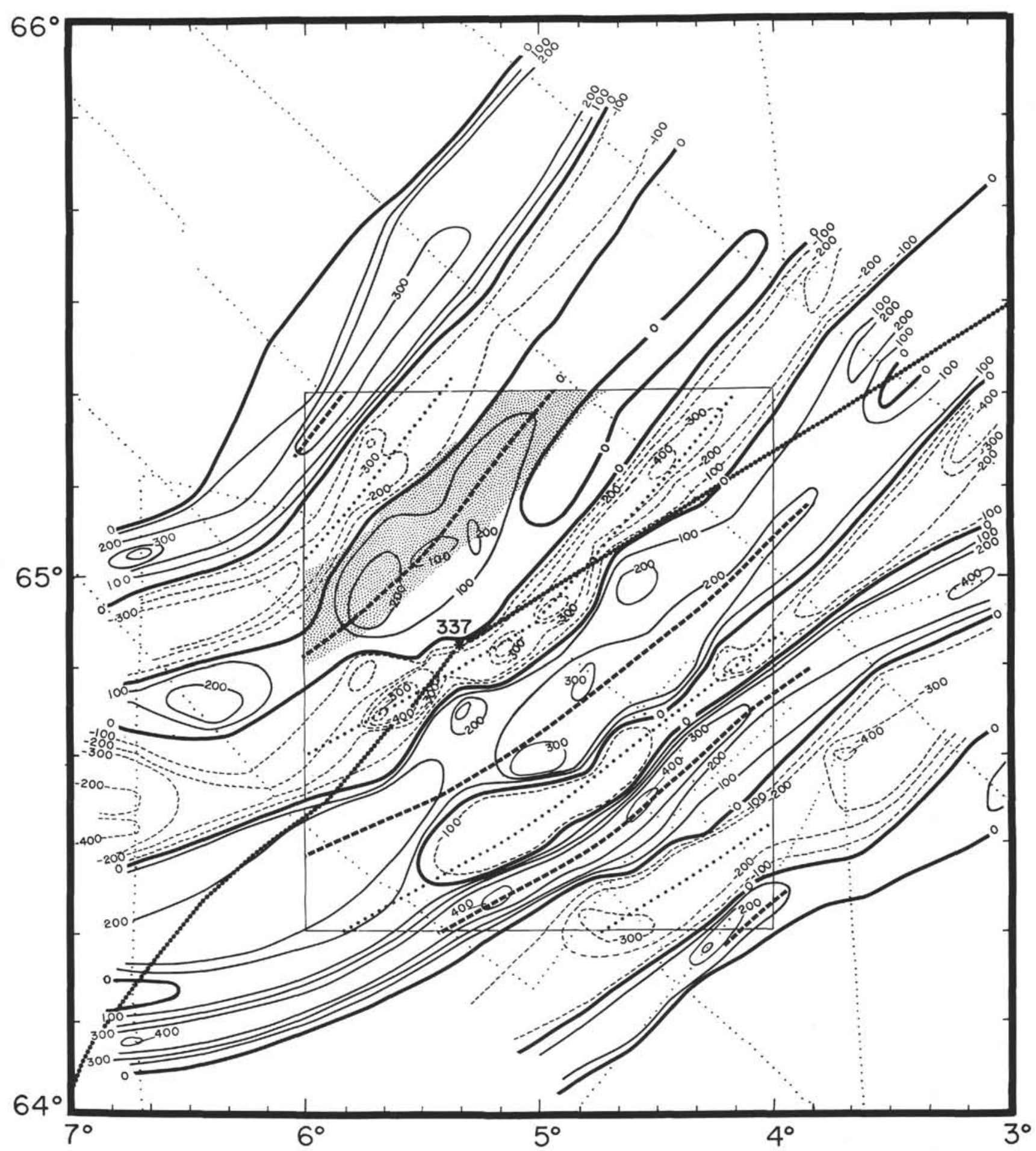

Figure 3. Total intensity magnetic map with regional field removed. The stippled area corresponds to depths greater than 3700 meters. The axes of the negative anomalies are shown by dotted lines, whereas the axes of the positive anomalies are shown by dashed lines. 


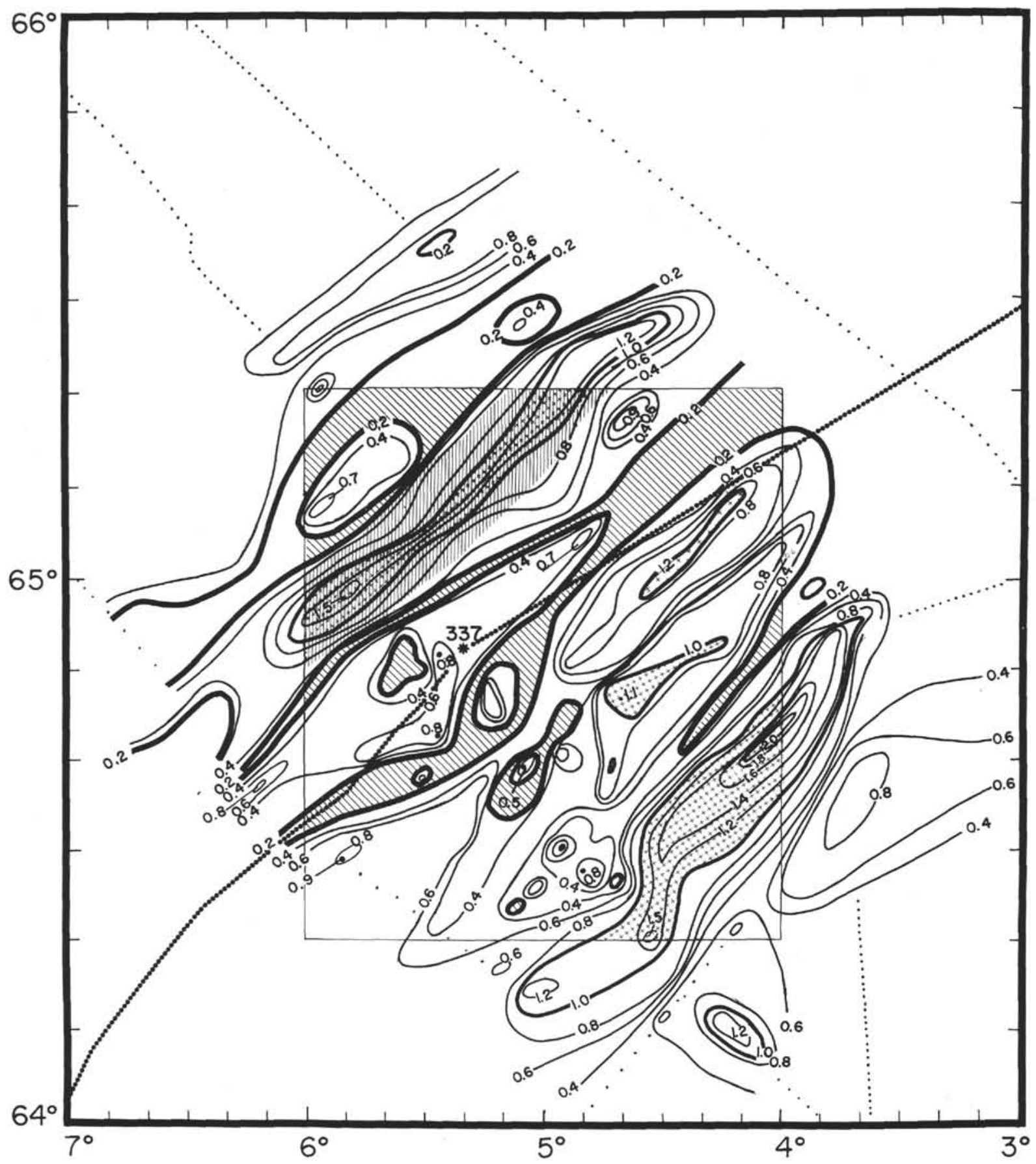

Figure 4. Sediment thickness obtained by reflection profiling. Sediment thickness less than 0.2 sec (two-way travel time) is shown by diagonal shading. Sediment thicknesses in excess of $1.0 \mathrm{sec}$ are shown by pattern with crosses. Areas of depths greater than 3700 meters in the extinct rift are shown by vertical shading. 


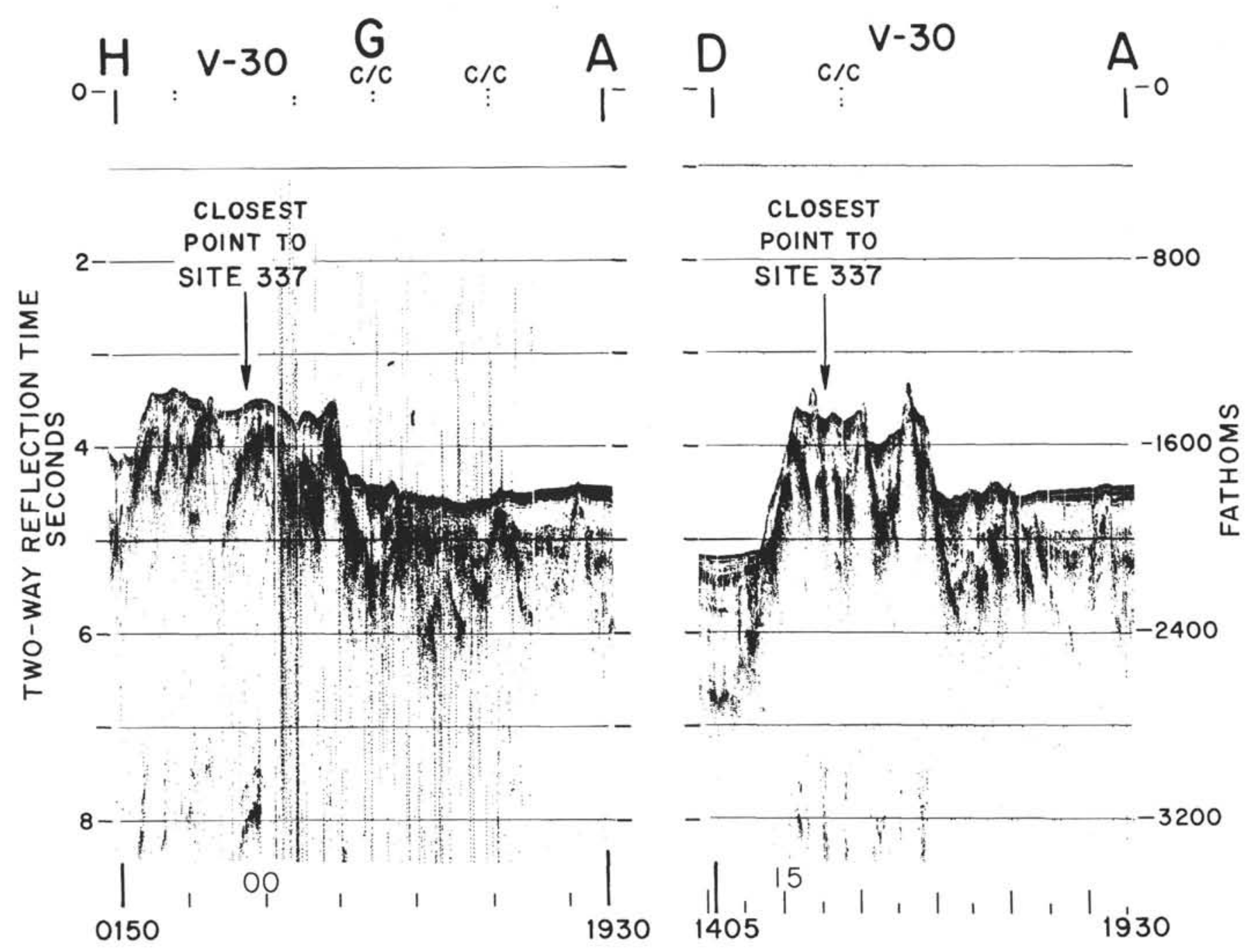

Figure 5. Vema 30 seismic reflection profiles near Site 337. The positions of points $H, D$, G, and A are located in Figure 1. 